\title{
Intra-National Trade as Channels of Spillovers in Developing Countries
}

\author{
Yong He \\ CERDI-CNRS, Université Clermont-Auvergne, Clermont-Ferrand, France
}

\begin{abstract}
We developed a model to explore the comparative advantage based intra-national trade in developing countries, as a contrast to models driven by increasing returns and agglomeration that prevail in the developed world. The model incorporates technological spillovers and trade. The findings suggest that the intra-national trade share of a region is inversely proportional to its technological level, and that economic growth diffuses along the intra-national trade network from the developed country, through the advanced regions of the developing country, into its less developed regions. Internal trade costs exert a multiplied hindering effect, stronger than that of border barriers, on national growth. The statistics derived from China's 2007 provincial input-output tables provide evidence in favor of the main theoretical findings.
\end{abstract}

JEL Classifications: F1, O1, O3, O4, R1

Keywords: Comparative Advantage-based Intra-national Trade, Intra-national Spillovers, Regional Input-output Tables, Regional Disparity, Endogenous Growth Model.

\footnotetext{
* Corresponding Author: Yong He; CERDI-CNRS, Université Clermont-Auvergne, 65 Bd. François Mitterrand, 63000, Clermont Ferrand, France, Tel: +33473177500, Fax : +33473177428, E-mail : yong.he@uca.fr.

Acknowledgements: The author would thank Cheng Jin, Sun Guang-Zhen and an anonymous reviewer for their comments and suggestions that significantly contributed to improving this study. 


\section{Introduction}

Intra-national trade can be thought to be more prevalent in developing than in developed economies. In addition, intra-national trade in the former is unevenly distributed. While advanced regions have a higher share of foreign trade, less developed regions may resort exclusively to internal trade. These features give rise to a number of questions for a research agenda. If intra-national trade shares differ across regions, what determines a region's choice between inter- and intra-national trade? What are the consequences of this unequal distribution? Openness is usually estimated as a major economic driving force for the developing world. Could intra-national trade, because of its substitution for international trade, be regarded as less development-oriented? Could intra-national trade be complementary to international trade, in the sense of prolonging international technological spillovers? More generally, what are the specific characteristics of intra-national trade in developing countries, and what role do they play in the development process?

These important questions, which currently lack theoretical investigations, motivate this study. The main objective of the study is to provide an analytical framework within which to answer these questions. In particular, the amplification of technological spillovers through intra-national trade in developing countries remains unexplored.

The next issue is how to approach this theme methodologically. The literature review explains why various approaches, notably Ohlin's neoclassical interregional trade theory and the new economic geography, which address the causes and effects of intra-national trade, have drawbacks in terms of analyses of intra-national trade in developing countries. It also explains why adopting a technological spillover model, while maintaining the spirit of Ohlin's comparative advantage, is necessary. This paper presents the model setting, the main findings, and the contributions of the study.

To begin with, the assumption that underlies this model is the existence of wide regional disparity in a typical developing country. This assumption is explained further in the next section. Because technological spillovers through trade and the imports of technological inputs cover the essential aspects of comparative advantage-based trade, this study examines a network, with numerous layers incorporating inter- and intra-national trades of intermediate goods. We describe a developing country, with multiple regions ranked by technological capability and characterized by differences in the number of varieties of intermediate goods at the beginning. We also describe a 
developed foreign country, which has a technological level higher than that of all regions in the developing country.

Because a region's production is a function of the number of varieties of intermediates, it must choose between inventing or importing and then imitating new intermediate goods. If importing, a region must further choose how much to import, as well as whether to do so from other advanced regions or from the developed country. Regions' choices are described by an endogenous growth model with an expanding variety of intermediate goods. Having shown that, under certain reasonable conditions, importation is always better for all regions, the model first derives an equation that determines the optimal number of varieties of intermediates a region seeks to employ. Then, an import equation is derived to determine the region's optimal number of imports and the ranges of new varieties of intermediates.

From these equations, intra-national trade shares are determined endogenously at the regional and national levels, based on a theory of a region's choice between intraand international trade. This choice is contingent on differentials in trade costs and in assimilation costs between intra- and international imports, emphasizing the high assimilation costs of new intermediates from foreign trade for less developed regions. In a typical South-North spillover model, two partners get to a steady state, where they equalize their growth rates, through their transitions. In contrast, in this study, the oneto-one dynamic analysis is extended to multiple regions, in which their choices based on different technological capabilities lead to the formation of a network connecting interand intra-national trades. Within this network, which has numerous layers, if all trade partners have reached their steady states, then the network reaches a steady state.

Three key results that characterize intra-national trade in developing countries are obtained. First, at the regional level, the rank and the number of imported new intermediates of a region are increasing in its technological capability, while its intranational trade share is decreasing in this capability. In a coordinated way, the intranational trade share increases with interregional technological inequality at the country level. Second, an intra-national trade network prolongs the technological spillover effects emanating from international trade, through the advanced regions, to the least developed regions. Thus, all partners involved in the trade network, initially with differing growth rates, reach their highest growth rates, benefiting from the foreign country. Third, within the network, internal trade costs exert a multiplied hindering effect on growth, which is stronger than an equivalent lifting of border barriers. The higher the country's interregional technological inequality, the larger is the difference between the effects of 
internal and external trade costs.

The main contribution of this study results from its analysis of the causes and effects of intra-national trade in developing countries. In comparison with intra-national trade in developed countries, where increasing returns and agglomeration are the driving forces, this study shows that the key features of it in developing countries remains comparative advantage-based in nature. Unlike in developed countries, which have narrow regional disparity, intra-national trade in developing countries exerts strong technological spillover effects.

More precisely, this study offers a formal presentation of the linkages between intraand international trade in developing countries. The first of the three results, on regions' choices between the two types of trade, illustrates the substitutive relationship between the two types of trade. This implies that, unlike in a developed country, where border effects could play a decisive role in determining the relative scopes of the two types of trade, this substitution in a developing country is, to a larger extent, explained by internal factors, notably by regional differences in the capability of imitating new technologies. As such, reducing border barriers (e.g., to promote openness) may produce a limited effect, owing to the persistence of internal forces underlying the demand for intranational trade. The second result on the spillover effects of the trade network elucidates the complementary relationship between the two types of trade and a promising prodevelopment effect of intra-national trade. The third result makes clear that, given the crucial role of internal trade costs, without a well-organized intra-national trade structure, foreign trade can only benefit a minority of advanced regions, excluding less developed regions from the globalization process. This result provides theoretical support for the necessity to improve internal market integration (Poncet 2005, World Bank 2005).

Another contribution of this study is in the empirical findings. Assessing the importance of intra-national trade to international trade in developing countries encounters difficulties in terms of data collection. Using China's 2007 provincial inputoutput tables, we establish a quantitative picture of the two types of trade, as well as their shares in regions with different development levels.

The rest of this paper is organized as follows. Section II provides an analytical review of existing literature. Section III builds a baseline model with which to describe regional behaviors in production, consumption, and technological innovation. Then, we set up the trade framework at the country level, before analyzing the central features of intra-national trade in a developing country. Section IV uses data on China to find empirical support for the predictions derived from the theory, and Section V derives the 
policy implications of our findings. Lastly, Section VI concludes the paper, including a description of possible areas for future research.

\section{Literature Review}

According to Krugman (2015), international and intra-national trade are both driven by either comparative advantage or increasing returns and agglomeration. Ohlin (1933) and the new economic geography have explored intra-national trade based on these observations.

In Ohlin's (1933) view, "regions have different factor endowments, while the factors within a region are essentially similar. ...it is assumed that the factors of production are inter-regionally immobile but intra-regionally freely mobile." (p.5) Differences in comparative costs embrace both necessary and sufficient conditions for interregional exchange. Each region specializes in the production in which its factors are relatively abundant and cheap, and then all regions gain from trade, rather than from staying in autarchy. Comparative advantage is the cause of international and intra-national trade.

Since 1990, two influential publications by Krugman (1991a, 1991b) marked the emergence of the new economic geography. The key idea of new economic geography originated from Isard (1956), in which Ohlin's assumption of interregional factor immobility was criticized as being unrealistic. Isard (p.52) deemed that a region should be defined as a district, à la Thünen, in which the force of increasing returns governs whether individuals and firms relocate. In new economic geography, both interregional and international trade are described from the point of view of location theory and agglomeration.

The explanatory power of the new economic geography depends crucially on the extent of possible factor mobility and an agglomeration process in order to take place. In a developed economy, this process occurs well, making regional disparity endogenous. Exogenous regional disparity refers to what Cronon (1991) calls first nature inequalities; there are natural differences in resource endowment, climate feature, and geographical characteristics among regions. In contrast, endogenous, or second-nature

\footnotetext{
'The two books on the new economic geography on which this review is based are Fujita, Krugman, and Venables (1999) and Combes, Mayer, and Thisse (2008).
} 
inequalities, are the result of human actions, such as factor mobility and agglomeration, to improve upon first-nature inequalities. Combes, Mayer, and Thisse (2008) claim the following in terms of the appropriateness of this approach to endogenous regional disparity for the developed world (p.15): "Our vantage point is, therefore, the expression of a methodological choice, i.e., that of identifying the microeconomic mechanisms that explain regional disparities in developed countries, which form Cronon's second nature." (Italics in the original.)

When applied to developing countries, this approach is hindered, because in these countries, the industrialization process is relatively new. Conglomeration, which parallels this process, is not yet a major force. Due to the high costs of mobility associated with the backwardness in transport infrastructure and institutional impediments, factor movement, labor, and capital meet serious obstacles. Therefore, the analysis must build on the initial structure associated with the inertia in change or on their exogenous regional disparity.

In accordance with the difference between exogenous and endogenous regional disparity, one of the intrinsic features that distinguish developing from developed countries is that, in the former, regional disparity remains wide, while in the latter, agglomeration and factor relocation have made it much smaller. ${ }^{2}$ This distinction is supported by several well-known studies. Williamson (1965) argued that industrialization is driven by the discovery and utilization of natural resources, such as coal and iron. These natural resources are often not distributed equally within the country. Thus, regional disparity tends to be larger, and will increase, up to a certain point. After this point, it will decrease owing to labor mobility, which reduces the income inequality between regions. Recently, Lessmann (2014) used a unique panel data set of spatial inequalities in 55 countries at different stages of economic development, covering the period 1980 to 2009 , and provided strong support for the existence of an inverted U-shaped relationship of regional inequality.

Therefore, to be able to capture the basic feature of intra-national trade in developing countries, without ignoring the growing role of the new economic geography, the general approach should follow that of Ohlin (1933), under the assumption of factor immobility and exogenous comparative advantage. Interregional trade in volume and in kind will be determined by regions' optimal choices, based on their comparative advantage.

At the same time, whereas Ohlin's view accommodates developing countries, it has

${ }^{2}$ Using Krugman's (2015) expressions, "America is flat" and "Americans are doing pretty much the same thing everywhere." 
at least two major limitations in dealing with the issue of intra-national trade in these countries. First, a comparative advantage can be driven by either factor endowment or technology as shown by Costinot (2009). Comparative advantage driven by factor endowment (e.g., rich in aluminum in one region and in iron in the other) does not necessarily entail regional disparity, while this disparity is always shaped by differences in technology. Often, differences in geographical and climatic conditions and in resource endowments among regions coincide with their differences in technological level. For instance, the inequality between the coastal and inland regions in China is one such case. For this reason, while keeping the spirit of comparative advantage and factor immobility, we adopt a technological approach to cope with exogenous regional differences. Second, while Ohlin (1933) derived interregional and international trade theories on the grounds of comparative advantage, nowhere was the trade-off between the two types of trade in regions analyzed. This is a key issue, because the two types of trade are substitutive. Thus, determining their respective scopes is necessary, which is not possible without a theory on region's choices between the two types of trade.

To overcome the first limitation, this study specifies a model on trade in technological inputs among regions. This choice is also based on two other arguments: 1) the trade of technological inputs to enhance the technological level captures the key aspect of comparative advantage-based trade; and 2) allowing for a dynamic analysis yields greater insight into the theory of intra-national trade.

The vast literature on technological spillovers motivates this approach. For more than 30 years, technological spillovers, especially spillovers through trade, have been analyzed along with international trade between developing and developed countries, as in Findlay (1978), Krugman (1979), Dollar (1986), and Grossman (1991). To extend these models to a regional analysis, the marked regional disparity within developing countries implies that 1) there is a strong internal technological demand, and 2) less developed regions have a relatively low technological absorption capability. The most important argument justifying intra-national spillovers is technological distance. $\mathrm{Fu}, \mathrm{Fu}$, and $\mathrm{Li}$ (2008) have shown that within developing countries, regional technology transfer takes place more effectively when the technological distance is small. Related to this argument, compared with international trade, intra-national trade is conjectured to offer lower, but more appropriate technology, and is less costly in terms of transport and more efficient in technology transfer. This is due to the proximity in language, institutions, and culture, as well as facilities in labor and capital mobility, knowledge communication, and learning and formation. 
Two kinds of models have been applied to delineate technological spillovers: those with an expanding variety of intermediates, and those of quality ladders. We chose the first approach, based on the seminal work of Ethier (1982) and Romer (1990) for its ability to adapt to a trade model. Owing to the use of higher technological input, final products are upgraded in terms of quality, design, and variety, even without necessarily buying sophistical equipment or changing production processes. There are many examples in the real world of this kind of innovation, where simply changing one or several components improves a product. Blalock and Veloso (2007) provide a typical case. A shoe producer switches to imported leather because of its better malleability, allowing the creation of more intricate shapes and, thus, enabling the production of shoes with greater value added. A stream of econometric papers such as Feenstra, Markusen, and Zeile (1992), Fernandes (2007), Kasahara and Rodrigue (2008), and Amiti and Konings (2008) have shown that importing intermediate goods raises productivity via learning, variety, or quality effects.

There is a second limitation of Ohlin's theory in coping with intra-national trade in developing countries: the absence of a choice theory between intra- and international trades by regions. Without more new components, the models of technological spillovers are still unable to incorporate this choice. To overcome this drawback, we draw on the approach describing how border effects result in international trade decreasing and withincountry trade increasing in line with McCallum (1995), Wei (1996), and Anderson and Wincoop (2003). This idea led to a number of empirical investigations in North American and European countries. They identified an important determinant of the relative shares between the two types of trade. However, in these studies, the focus was on international trade and its costs. The choices between the two types of trade in developing countries are (as this study attempts to show), to a larger extent, shaped by internal forces such as technological capabilities and their associated assimilation costs. For trade costs, while border trade barriers are a central concern in international economics, internal trade costs have recently garnered increased interest. Examples of such studies include Young (2000), Poncet (2005), and Tombe and Zhu (2015). In addition, borrowing from these works, this study formulates regional choices of intra-national trade shares by comparing external and internal trading, as well as their respective assimilation costs. 


\section{Theoretical Analysis}

\section{A. Baseline model}

This model accounts for regional behaviors in production, consumption, research, and trade, with an expanding variety of intermediate goods, and is adopted from Barro and Sala-i-Martin (2004). It is used to explore the workings of regional economies in a developing country in two cases: when the region invents its own intermediates, and when it imitates intermediates after importing them. This model then defines the trade structure among regions and between regions and the foreign country.

\section{Regions}

A developing country is composed of multiple regions. This implies that the country takes a certain size and a certain level of development (since, as explained previously, regional inequality goes with development). The excluded cases are small developing countries with only one region, or with few regions without significant differences.

In this section, we first derive the optimal conditions for producing final goods and for a representative consumer, in the case of self-invention. Then, we obtain the conditions for the case of imitation after importing new intermediates.

There is one sector producing final goods, with a large number of competitive producers. The production function of a representative firm in region $i$ is

$$
Y_{i}=A_{i} L_{i}^{1-\alpha} \sum_{j=1}^{n i}\left(X_{i j}\right)^{\alpha}=A_{i} L^{1-\alpha} X_{j}^{\alpha} N_{i}
$$

where $A_{i}>0$ is the parameter of productivity, and $0<\alpha<1$ is assumed to be the same for all regions. Then, $Y_{i}$ denotes output, $L_{i}$ denotes the labor input, and is a constant $\left(L_{i}=L\right), X_{i j}$ is the employment of the $j^{\text {th }}$ variety of intermediates, and $N_{i}$ is the number of varieties of intermediates. Output is an increasing function of $N_{i}$. With the equalization of marginal productivity of each intermediate good to its price, the demand for each intermediate is:

$$
X_{j}=L\left(\frac{A_{i} \alpha}{P_{j}}\right)^{1 /(1-\alpha)}
$$

Wages, equal to the marginal product of labor, results in: 


$$
w_{i}=(1-\alpha) A_{i} L^{-\alpha} X_{j}^{\alpha} N_{i}
$$

In this optimization by the producers of final good $Y_{i}, X_{j}$, and $w_{i}$, are dependent on the price of the intermediate good $j$, namely $P_{j}$ (which is unknown, and is subject to the optimal production of the intermediates). Then, this production can be described as follows.

The varieties of intermediates are considered to be invented chronologically from 1 to $n$. This order can also be understood as the advancement in the technological level (the most advanced being the most recently invented product). At the starting period, $N_{i}(0)>0$, implying that region $i$ always knew how to produce at least one type of intermediate good. If the region invents its own intermediates following research, then when the new intermediate good $j$ has been invented, the present value of the returns at time $t$ from discovering the $j$ intermediate good at date $v$ must be:

$$
V_{i j}(t)=V_{i}(t)=\int_{t}^{\infty} \pi_{j}(v) e^{-\tilde{r}_{i}(t, v) *(v-t)} d v
$$

where $\tilde{r}_{i} \equiv\left[1 /\left(v^{-} t\right)\right] \int_{t}^{v} r_{i}(\omega) d \omega$ is the average interest rate between times $t$ and $v$, and $\pi_{j}$ is the profit flow of intermediate good $j$.

With marginal and average costs normalized to unity, the profit function maximized by a research firm is:

$$
\pi_{j}(v)=\left[p_{j}(v)-1\right] X_{j}(v)
$$

Here, $X_{j}(v)$ is the demand function of $j$ that can be substituted with the value defined by Equation (2). By maximizing profit at the monopoly price (because of the inventor's monopoly position at the moment of the invention), the price of the intermediate is a constant markup over marginal cost:

$$
p_{i j}=p_{i}=\frac{1}{\alpha}
$$

Substituting this result into Equation (2), the demand for intermediate good $j$ is:

$$
X_{j}=L A_{i}^{1 /(1-\alpha)} \alpha^{2 /(1-\alpha)}
$$

which we can substitute into Equation (5), and also substitute for $p_{j}$, from Equation (6), 
into Equation (5). Then, the flow of monopoly profit from the sale of the $j^{\text {th }}$ intermediate good is:

$$
\pi_{i j}=\pi_{i}=L A_{i}^{1 /(1-\alpha)}(1-\alpha) \alpha^{(1+\alpha) /(1-\alpha)}
$$

Substituting this into Equation (4), the inventor's net present value of profit at time $t$ is calculated with $r_{i}$ still unknown.

The cost of inventing a new intermediate is assumed to be a fixed amount of goods:

$$
R \& D \operatorname{cost}_{i}=\eta_{i}
$$

Here, $\eta_{i}$ measures region $i$ 's capability of invention. This capability for higher lower values of $\eta_{i}$. The decision to conduct R\&D by a research firm is taken when $V_{i}(t)>\eta_{i}$. At equilibrium, the free-entry condition leads to:

$$
V_{i}(t)=\eta_{i}
$$

Following Barro and Sala-i-Martin (2004), we can differentiate the free-entry condition in Equation (8) with respect to time, using the formula for $V_{i}(t)$ from Equation (4). Taking into account the definition of $\tilde{r}_{i}$, the instantaneous rate of return from buying the firm is the profit rate plus the capital gains that accrue from changes in the value of the firm:

$$
r_{i}(t)=\frac{\pi_{i}}{V_{i}(t)}+\frac{\dot{v}_{i}(t)}{V_{i}(t)}
$$

Since $\eta_{i}$ is constant, the free-entry condition in Equation (8) implies $\dot{v}_{i}=0$. Taking into account Equation (8), it follows that the interest rate is constant and equal to:

$$
r_{i}(t)=r_{i}=\pi_{i} / \eta_{i}
$$

Lastly, the household of region $i$ maximizes a utility function over an infinite horizon:

$$
U_{i}=\int_{0}^{\infty}\left(\frac{c_{i}^{1-\theta}-1}{1-\theta}\right) e^{-\rho t} d t
$$

where $c_{i}$ is consumption, $\theta>0$, is the elasticity of the marginal utility, and $\rho$ is the 
rate of time preference. Here, $\rho$ and $\theta$ are assumed to be the same for all regions.

The budget constraint condition of region $i$ is:

$$
Y_{i}=C_{i}+N_{i} X_{j}+V_{i} \dot{N}_{i}
$$

This constraint is valid for both self-invention and imitation via importation (the latter will be dealt with subsequently). This means that total output, $Y_{i}$, is equal to total consumption, $C_{i}$, plus the resources devoted to the production of intermediates, $N_{i} X_{j}$, plus the resources devoted to the invention (imitation) of intermediates, $V_{i} \dot{N}_{i}$. These are also the unit cost of the invented (imitated) intermediate multiplied by the quantity.

Using the method of optimal control, along with some algebra, we obtain two equations of motion:

$$
\begin{gathered}
\frac{\dot{N}_{i}}{N_{i}}=\frac{1}{\eta_{i}}\left[\pi_{i} \frac{(1+\alpha)}{\alpha}-\frac{C_{i}}{N_{i}}\right] \\
\frac{\dot{C}_{i}}{C_{i}}=\frac{1}{\theta}\left(\frac{\pi_{i}}{\eta_{i}}-\rho\right)
\end{gathered}
$$

This construction delineates a close model in which the increase in $N$ hinges on invention. Now, we can study the case in which region $i$ improves its productivity through imitation, after importing new intermediates from a more advanced region or country. In what follows, the case with trade refers to imitation after the importation of new varieties of intermediates, rather than self-invention. Hence, the terms "trade" and "imitation" are used interchangeably.

Unlike in the case of self-invention, where the cost, as defined in Equation (7), is $\eta_{i}$, in the case of imitation, region $i$ must pay for a trade cost and then expend resources to learn and adapt the good to its environment. The latter is called an assimilation cost. Thus, the cost of imitation is assumed to be:

$$
\text { Imitation cost } t_{i}=T_{i} F_{i} \widehat{N}_{i} \eta_{i}
$$

where $F_{i} \widehat{N}_{i} \eta_{i}$ measures the assimilation cost, with $F_{i}(\geq 1)$ as a parameter scaling this cost. Then, $F_{i}$ is set to differentiate between intra- and international trade in terms of assimilation costs. This is discussed in more detail a little later. Taking an iceberg form 
$T_{i}(\geq 1)$ is a parameter that scales the trade cost, such that the value of this cost is $\left(T_{i}-1\right) F_{i} \widehat{N}_{i} \eta_{i} . \widehat{N}_{i}=N_{i} / N_{h}$, with $N_{h}$ as the number of varieties of intermediates of $h$. Here, $h$ is a potential exporting region or country with higher $N$ than that of region $i$, or $N_{i} / N_{h}<1$.

As such, together with $T_{i}$ and $F_{i}$, two factors determine the cost of imitation: 1) the higher the invention capability (the lower the $\eta_{i}$ ), the lower is the cost of imitation; and 2) as $N_{i}$ increases relative to $N_{h}$, resulting in a higher ratio of the region's intermediate number to that of $h: \widehat{N}_{i}$, the cost of imitation rises. However, for regions with higher $\eta$, to reach a certain level of $\widehat{N}_{i}$, they must bear higher costs of imitation. This is a realistic definition, stating that less developed regions face higher and increasing technological barriers. ${ }^{3}$

Because $T_{i} F_{i}$ shapes the extent of imitation, if it exceeds a certain level, no trade occurs. Equation (7) and Equation (15) imply that the condition for region $i$ to choose imitation over self-invention is $T_{i} F_{i} \widehat{N}_{i} \eta_{i}<\eta_{i}$, or $T_{i} F_{i}<1 / \widehat{N}_{i}$. If this inequality is not ensured in the case of excessive imitation costs, the region has to choose self-invention. In what follows, with the case of imitation, this inequality is assumed to always hold.

With these changes in the cost of imitation, two changes occur with regard to the model of self-invention. First, the free-entry condition becomes:

$$
V_{i}(t)=T_{i} F_{i} \widehat{N}_{i} \eta_{i}
$$

In turn, Equation (9) leads to Equation (10) becoming:

$$
r_{i}(t)=r_{i}=\frac{\pi_{i}}{T_{i} F_{i} \widehat{N}_{i} \eta_{i}}+\frac{\dot{\hat{N}}_{i}}{\widehat{N}_{i}} .
$$

In contrast to the model of self-invention, there is a term $\hat{\widehat{N}}_{i} / \widehat{N}_{i}$ because $N_{i} / N_{h}$ is increasing in Equation (8.1), implying a capital gain at the rate $\dot{\hat{N}}_{i} / \widehat{N}_{i}$.

With trade, the cost of invention in Equation (13) is replaced by the cost of imitation. For region $i$, the equation of motion of $N$ in the case of trade becomes:

$$
\frac{\dot{N}_{i}}{N_{i}}=\frac{1}{T_{i} F_{i} \widehat{N}_{i} \eta_{i}}\left[\pi_{i} \frac{(1+\alpha)}{\alpha}-\frac{C_{i}}{N_{i}}\right] .
$$

\footnotetext{
${ }^{3}$ This also implies that goods that are easier to imitate are copied first. Thus, the region where the highest range of intermediate goods is indexed as $j$ will rationally start to choose to import $j+1$, then $j+2$, and so on.
} 
With the Euler equation $\dot{C}_{i} / C_{i}=(1 / \theta)\left(r_{i}-\rho\right)$, and using Equation (10.1) in place of $r_{i}$, we have:

$$
\frac{\dot{C}_{i}}{C_{i}}=\frac{1}{\theta}\left(\frac{\pi_{i}}{T_{i} F_{i} \widehat{N}_{i} \eta_{i}}+\frac{\dot{\hat{N}}_{i}}{\widehat{N}_{i}}-\rho\right)
$$

Equations (13.1) and (14.1) in the case of importing new intermediates, compared with Equations (13) and (14) in the case of self-invention, constitute the basis for the subsequent intra-national trade analysis.

\section{Setting up the trade structure}

Considering a large number of regions will make the model tractability difficult. Thus, we ignore the spatial distribution of the regions and the geometrical distances among them. ${ }^{4}$ In addition, we assume that all regions have the same size in terms of population and labor $\left(L_{i}=L\right)$. The regions are ranked by technological level. Denote a region $R_{i}(i=1, \ldots, m)$. Here, $R_{1}$ and $R_{m}$ are the regions with the highest and the lowest technological levels, respectively. The positions of the regions can be expressed as $G\left(R_{i-1}\right) \geq G\left(R_{i}\right) \geq G\left(R_{i+1}\right)$, where $G$ stands for technological level. There are three possibilities: 1) if they are equal, there is no regional technological inequality; 2) if they are unequal $(>$ or $<$ ), all regions are strictly unequal in technological level; and 3) if we have $\geq$ or $\leq$, there is a mixture of the two cases.

The assumption of exogenous regional disparity is made by the two parameters set to be exogenous and invariable over time: $A_{i}$, productivity, and $\eta_{i}$, the cost of invention. Since the regions are ranked by technological level, this i mplies $A_{1} \geq \cdots \geq A_{i-1} \geq A_{i} \geq A_{i+1} \geq \cdots \geq A_{m}$, and $\eta_{1} \leq \cdots \leq \eta_{i-1} \leq \eta_{i} \leq \eta_{i+1} \leq \cdots \leq \eta_{m}$; thus, $A_{i}$ and $\eta_{i}$ coincide in ordinal number. While $N_{i}(t)$ is endogenous, it can be shown that, with or without trade, $N_{1}(t) \geq \cdots \geq N_{i-1}(t) \geq$ $N_{i}(t) \geq N_{i+1}(t) \geq \cdots \geq N_{m}(t)$ always hold. In other words, no technological switchovers occur and the technological ranks of all regions will be unchanged along the entire time path.

Along with the developing country, there is a foreign country, denoted $H$, that has the same size of regions $\left(L_{H}=L_{i}=L\right)$, and its technological level is higher than region 1 of the developing country, implying $A_{H}>A_{1}, \eta_{H}<\eta_{1}$, and $N_{H}(t)>N_{1}(t)$. The number of

\footnotetext{
${ }^{4}$ The importance of distance can be considered to be attenuated in a developing country of a certain size, in that each region is surrounded by a number of regions with various technological levels.
} 
varieties of intermediates of any region $i$ constitutes a subset of $N_{H}$. These definitions of exogenous $A_{H}$ and $\eta_{H}$ imply that $H$ always has the capability to keep its technological leadership. The behavior of $H$ in production, consumption, and invention of new intermediates can also be described by the baseline model of self-invention, with all variables indexed with $H$.

Note that trade has both a quantitative and a qualitative dimension. Quantitatively, the number of varieties of intermediates to import must be chosen by a region. Qualitatively, the varieties of intermediates are ranked according to their technological advancement, implying that the higher a region's technological level, the higher its range of imported intermediates will be.

Comparative advantage-based trade infers that less developed regions import a higher range of varieties of intermediates from more advanced regions (foreign country). In return, they export their lower range intermediates to these regions (foreign country). Thus, the trade process in the model, focusing on the import of new varieties of intermediates, follows a typical South-North trade pattern. Trade is either international or intra-national. Divisions by regions are addressed a little later. We ignore intraregional trade and only refer to inter-regional trade as intra-national trade. Because the prices of all varieties are identical, their quantity and value are equivalent. For the sake of tractability, we assume that for regions importing a higher range of intermediates, by exporting a lower range intermediates equivalent in value, trade is balanced at every point in time. As such, the import of intermediates is exactly half the trade, which means the import and trade of intermediates can be used interchangeably. ${ }^{6}$

Lastly, it is assumed that after trade at a total cost $T_{i} F_{i} \eta_{i} \widehat{N}_{i}$, the imported new varieties are completely assimilated, in the sense that region $i$ then has the capability to produce these goods.

\section{B. Steady state and transitional dynamics}

At the steady state, by definition, after trade, the growth rates of $N$ between $i$ and $h$ become equal, implying $\hat{N}_{i} / \widehat{N}_{i}=0$. Then, because (as can be readily shown) the growth

\footnotetext{
${ }^{5}$ For instance, region $A$ knows how to produce varieties 1 20, and region $B$ knows how to produce varieties $1 \sim 10$. If both seek to import 10 new varieties, then for region $A$, the imported varieties are 21 30, which are higher than those of region $B$, ranging from $11 \sim 20$.

${ }^{6}$ The incentive for advanced regions (foreign country) to trade with a higher range for a lower range intermediates could be that, for instance, concentrating on the higher range of intermediates favors the invention of new intermediates.
} 
rates of $C$ and $N$ are equal at the steady state, given $\chi_{i}=C_{i} / N_{i}, \dot{\chi}_{i} / \chi_{i}=0$ is also a steadystate condition.

As $H$, the foreign country, is potentially able to offer new varieties of intermediates to all regions, we consider the case in which all regions only trade with the foreign country. As such, the obtained intermediate numbers among regions become comparable on a uniform basis. The index $h$ is now replaced by $H, \widehat{N}_{i}=N_{i} / N_{H}$.

With the operations introduced in the Appendix, Equation (A5) gives:

$$
\widehat{N}_{i}^{*}=\frac{1}{T_{i} F_{i}} \frac{G_{i}}{G_{H}}
$$

where $\widehat{N}_{i}^{*}$ is the steady-state ratio of region $i$ 's intermediate number to that of the foreign country, $G_{i}=\frac{A_{i}^{1 /(1-\alpha)}}{\eta_{i}}$, and $G_{H}=\frac{A_{H}{ }^{1 /(1-\alpha)}}{\eta_{H}}$.

Equation (16) determines the optimal number of varieties of intermediates of region $i$. As, previously defined, $\eta$ is decreasing in $A$. Then, for each region, there is a unique value of $\boldsymbol{G}$ that measures the region's technological level. Equation (16) states that, for a given $G_{H}, \widehat{N}_{i}^{*}$ is determined by $G_{i}$, the technological level of region $i$. The higher $G_{i}$ is, the larger its optimal number of varieties is. Equation (16) underlies all subsequent analyses determining trade volumes by region and intra-national trade shares at the regional and national levels, as well as the formation of an intra-national trade network, with its spillover mechanism. The rationale behind Equation (16) is the trade-off between the benefit from increasing the number of varieties and the cost of imitation that is inversely related to the region's technological capability.

Correspondingly, the steady-state value of $\chi_{i}$, from Equation (A6) in the Appendix, is:

$$
\chi_{i}^{*}=\pi_{i}\left(\frac{1+\alpha}{\alpha}+\frac{\gamma_{H}}{\gamma_{H} \theta+\rho}\right)
$$

This equation implies that because $\pi_{i}$, from Equation (5.1), is increasing in $A_{i}$, the steady-state consumption of a region is also determined by the region's technological capability.

From Equation (A1) and Equation (A2) in the Appendix, $\partial \hat{\hat{N}}_{i} / \partial \dot{x}_{i}<0$ and $\partial \dot{x}_{i} / \partial \widehat{N}_{i}<0$, respectively. Thus, the regions follow a saddle path leading to their steady state. For the transitional dynamics, from Equations (13.1) and (14.1), during the transition, the 
term $\dot{\hat{N}}_{i} / \widehat{N}_{i}>0$ introduces a dynamism that ensures a growth rate higher than that at the steady state. The monotonic increase of $\widehat{N}_{i}$ and the decline of $\dot{\hat{N}}_{i} / \widehat{N}_{i}$ imply a monotonic decline in the growth rate of consumption, which converges to its steady-state level. Nevertheless, regions' technological capabilities do not make a difference to the speed of convergence. Conventionally, the speed of convergence $(\beta)$ towards the steady state is derived from Equation (A1) in the Appendix. Here, $\beta=-\partial \dot{\hat{N}}_{i} / \partial \widehat{N}_{i}=\gamma_{H}$, where $\gamma_{H}$ is the growth rate of the foreign country, means that the speed of convergence is identical across regions.

\section{Gains from trade and trade volumes by regions}

Comparing the equation of motion for trade (13.1) and that for self-invention (13), for any region, since $1 / \widehat{N}_{i}>T_{i} F_{i}$ lways holds, the growth rate of $N$ with trade is higher than that with self-invention. Similarly, from Equation (14) and Equation (14.1), the growth rate of consumption improves for trade. Because the growth rate of intermediate goods can readily be shown to be equal to that of production, trade also improves production growth.

The import volume of new intermediates by region $i$ can be evaluated around the steady state with the optimal number of varieties of intermediates provided by Equation (16). This import number can be treated as the import volume, because the latter is just this number multiplied by a constant, $X_{j}$, defined by Equation (2.1).

With $\gamma_{H}$ as the growth rate of $N$ of the foreign country $H$, at the steady state, it is also the growth rate for region $i$. The region's number of intermediate goods without imports, evaluated at the steady state, $N_{i 0}^{*}$, is equal to $\frac{1}{1+\gamma_{H}} N_{i}^{*}$. With this relationship, and applying Equation (16), the number of imported new varieties of intermediates evaluated at the steady state is:

$$
M_{i}=N_{i}^{*}-N_{i 0}^{*}=\left(\frac{\gamma_{H}}{1+\gamma_{H}}\right) \frac{1}{T_{i} F_{i}}\left(G_{i} / G_{H}\right) N_{H} .
$$

Equation (18) is the import equation that accounts for the import behavior of region $i$. It defines the quantitative and qualitative features of regional imports. Quantitatively, it states that, all else being equal, the number of imported new varieties of intermediates, or the trade volume, is increasing in the region's technological level. Qualitatively, it implies that the higher a region's technological level, the higher is its average range of 
imported new intermediates.

\section{Choices between inter- and intra-national trades}

Previously, the optimal import volume of $N$ was determined by assuming that all regions trade with the foreign country. However, all regions except that with the highest technological capability can choose to import new intermediates from either the foreign country or from other, more advanced regions. This section derives the rule where the ratios of intra-national trade to total trade are determined by regions. Given these choices, this ratio at the country level can also be fixed.

To begin with, in this over-simplified model, the prices of regional and international intermediates are the same, which means we cannot address the substitutability between domestic and foreign goods based on prices and exchanges rates (Betts and Devereux 1996, and Devereux 1997). However, we can deal with the choice between the two types of trade as a function of their respective trade costs. The parameter $T_{i} F_{i}$ (recall that $\mathrm{T}$ and $\mathrm{F}$ scale the trade and assimilation costs, respectively) can be indexed as $T_{i f} F_{i f}$. Here, $f=1$ if international trade is chosen, and $f=0$ if intra-national trade is chosen. Logically, all regions comply with the following choice rule for the same kind of intermediate good:

$$
\text { Choice }_{i}=\left\{\begin{array}{c}
\text { international trade if either } T_{i 1} F_{i 1}<T_{i 0} F_{i 0}, \\
\text { or the good unavailable in internal market } \\
\text { intra-national trade otherwise. }
\end{array}\right.
$$

The following arguments justify what we call the normal case, in accordance with conventional wisdom, in which $T_{i 0} F_{i 0}<T_{i 1} F_{i 1}$ holds for all $i$. This results in regions choosing intra-national trade for all new intermediates that can be obtained from other regions, and choosing foreign trade only for new intermediates unavailable within the country. Some exceptional cases with $T_{i 1} F_{i 1}<T_{i 0} F_{i 0}$ will be addressed last.

We examine the first of the two components of imitation cost, namely trade cost. For the same kind of goods, internal trade costs are normally not higher than the external trade cost, for two reasons. First, unlike international trade, there are no formal trade tariffs within a country. Second, owing to the backwardness of the transport 
infrastructure in a typical developing country, and the pervasive influence of the distance variable on trade (Isard and Merton 1954), internal trade is favored for lower transport costs (except in those regions located near the border).

Intra-national trade, especially in technological input, has a considerable advantage in the second component of the imitation cost, namely assimilation cost, from at least two aspects: 1) similarities in culture and language reduce communication costs and enhance understanding and learning; and 2) proximity in geometrical distance reduces assimilation costs by obtaining easier and quicker acquisitions of know-how via teaching, training, after-sales service, and technical assistance. These assertions have strong backing from a number of recent works. Cultural similarity is an important determinant of bilateral trade volumes (Felbermayr and Toubal 2010). A common language promotes bilateral trade (Melitz 2008). Language barriers and geographic distance are identified as two determining factors of R\&D productivity spillovers (Keller 2001). With the recognition of cultural and language restraints, many studies have examined how to reduce intercultural communication costs in international business (Schmidt et al. 2007).

Therefore, in a normal case, grounded in realism, international imitation costs are higher than intra-national costs.

The regions with the highest technological level have to choose international trade. Their import behavior is defined by:

$$
M_{i A}=\left(\frac{\gamma_{H}}{1+\gamma_{H}}\right) \frac{1}{T_{i 1} F_{i 1}}\left(G_{i} / G_{H}\right) N_{H}
$$

For regions that choose intra-national trade only, their import equation becomes:

$$
M_{i B}=\left(\frac{\gamma_{\bar{h}}}{1+\gamma_{\bar{h}}}\right) \frac{1}{T_{i 0} F_{i 0}}\left(G_{i} / G_{\bar{h}}\right) N_{\bar{h}}
$$

where $\bar{h}$ indexes a more advanced region from which region $i$ imports new intermediates.

More generally, for regions ranked by technological level, defining a region $k$, with technological level $G_{k}$ such that it attains $N_{k}^{*}$, imports of new intermediates are entirely satisfied internally. This is so that all regions with technological levels equal or lower than $G_{k}$ merely import new intermediates intra-nationally. Then, we have the following choice equation determining the intra-national trade ratio at the regional level in the normal case: 


$$
\text { Intra-national trade ratio }{ }_{i}= \begin{cases}1 & \text { if } i \geq k \\ \varphi_{i} & \text { if } 1<i<k,\left(0<\varphi_{i}<1, \text { and } \partial \varphi_{i} / \partial_{i}>0\right) . \\ 0 & \text { if } i=1\end{cases}
$$

For region 1 , the intra-nationally imported new varieties of intermediates are 0 . The regions with lower technological levels will choose higher proportions of intra-national imports. The regions with technological levels equal to or lower than that of region $k$ only import new varieties intra-nationally. More generally, the choice equation states that the lower a region's technological level, the higher is its intra-national import ratio of new intermediates.

For regions that have a share $\varphi_{i}$ of intra-national trade, their import equation is approximately:

$$
M_{i}=G_{i}\left[\left(\frac{\gamma_{\bar{h}}}{1+\gamma_{\bar{h}}}\right) \frac{\varphi_{i}}{T_{i 0} F_{i 0}}\left(N_{\bar{h}} / G_{\bar{h}}\right)+\left(\frac{\gamma_{H}}{1+\gamma_{H}}\right) \frac{\left(1-\varphi_{i}\right)}{T_{i 1} F_{i 1}}\left(N_{H} / G_{H}\right)\right] .
$$

Based on Equation (18.1), Equation (18.2), and Equation (18.3), we can define the intra-national trade share of country $I M$. At the steady state:

$$
I M=\frac{\left(\frac{\gamma_{\bar{h}}}{1+\gamma_{\bar{h}}}\right)\left(N_{\bar{h}} / G_{\bar{h}}\right)\left(\sum_{i=k}^{m} \frac{G_{i}}{T_{i 0} F_{i 0}}+\sum_{i=2}^{k-1} \frac{\varphi_{i} G_{i}}{T_{i 0} F_{i 0}}\right)}{\sum_{i=1}^{m} \Delta}
$$

where the denominator is equal to the sum of imports of all regions defined by Equation (18.1), Equation (18.2), and Equation (18.3).

Equation (21) allows us to show that the national intra-national trade share is shaped by regional technological inequality. Expanding the numerator into two additional terms, the left and right terms measure the effects of the group of regions with a lower technological level and that with a higher technological level, respectively. The general impact of regional technological inequality on the intra-national trade share is clear. If regional technological inequality is in decline and approaches zero, then the left term will decrease and converge to zero, while the right term, $\varphi$ decreases and converges to zero. Thus, the intra-national trade share decreases and tends to disappear. With the reduction of regional technological inequality, comparative advantage-based intra-national trade progressively decreases, and is replaced by international trade. 
Finally, we state what happens beyond the normal case. The government of region $i$ is unable to influence trade costs and assimilation costs associated with foreign imports. However, it is able to influence the trade costs and assimilation costs associated with trade with other regions through taxation or administrative regulation that imposes extra costs. It is feasible that the regional government behaves in a manner that leads to an internal cost that is higher than the external cost. This could happen either at exceptional moments (e.g., war) or when the regional government seeks excessive fiscal revenue. Another possibility is that the government is so motivated by protecting its infant industries that it prevents some imports from other regions. In particular, with administrative obstacles that restrain or prohibit some imports, internal trade barriers can be considered to be higher than international trade barriers. As such, two exceptional cases could occur: 1) regions with $T_{i 1}<T_{i 0}$, and $T_{i 1} F_{i 1}<1 / \widehat{N}_{i}$ will substitute international trade for intra-national trade. Otherwise, the regions have to stay in self-invention. Thus, we conclude that in the presence of an exceptional case, in which internal trade costs are higher than external trade costs, it is uncertain whether the intra-national trade share at the national level is higher or lower than in the normal case. However, in the interest of realism, this extreme case seldom appears for certain moments or for certain goods.

\section{E. Trade network and spillover mechanism}

Until now, trade has not been dealt with as a network. Intra-national trade as a network has more than one trade layer. The formation of a hierarchical trade network can be explained by regions' rational choices based on technological distance. This is fully implied by this model. To illustrate this, Equation (A5): $\widehat{N}_{i}^{*}=\frac{1}{T_{i} F_{i}} \frac{G_{i}}{G_{h}}$, which determines the optimal number of varieties, can be applied to region $i$ 's choice of region from which to import intermediates among all available regions with higher technology. In this case, $F_{i}$, the assimilation cost, becomes a variable that depends on the technological distance from the chosen region, and is lower for lower distances. The maximization of $\widehat{N}_{i}^{*}$ implies a minimization of the technological distance when choosing a trade partner. The logic behind the model is that the region importing new intermediates from other regions with various technological capabilities bears various assimilation costs. Every region seeking to import from the advanced region with the lowest technological distance makes the trade network with multiple trade layers endogenous. 
Because regions could gain from importing rather than inventing new intermediates, they all engage in imports and, thus, form a trade network. Trade networks in the real world are exceedingly complicated. Here, focusing on the differences in technological levels, without considering geographical location, the network connecting inter- and intra-national trades can be featured as a mixture of the two extreme trade patterns.

\section{Figure 1. Two extreme trade patterns}

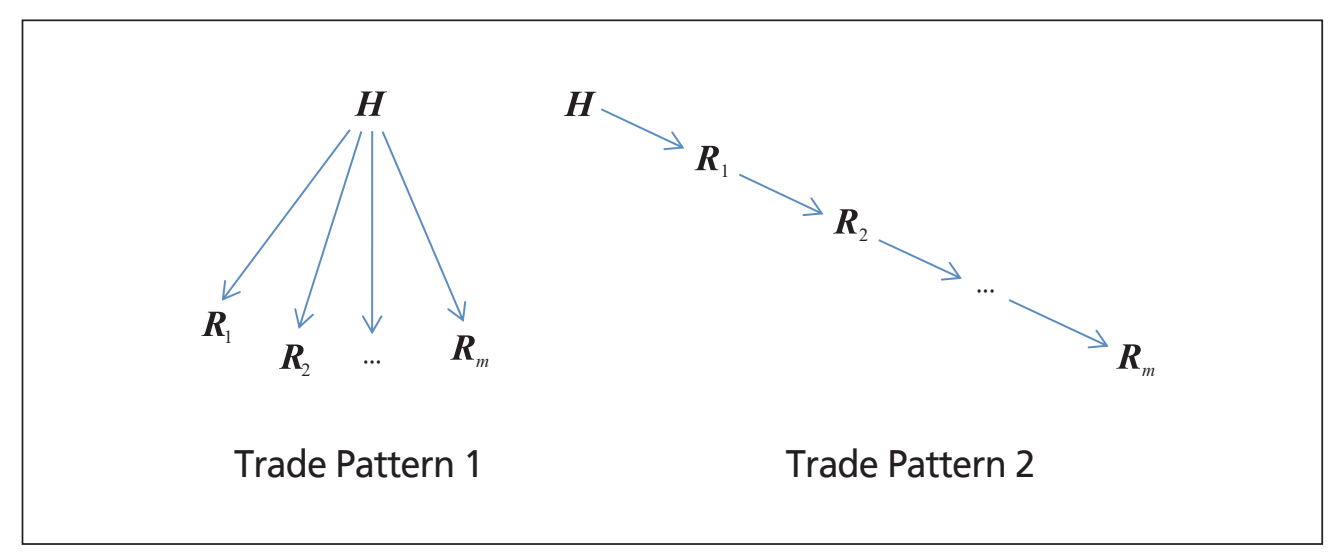

(Note) $H$ is the foreign country. The arrows reflect the export direction of new intermediates, and $R_{1}$ to $R_{m}$ denote the $m$ regions along which technological levels are equal (in trade pattern 1) or decreasing (in trade pattern 2).

(Source) Author.

In trade pattern 1, all regions import their new intermediates from the foreign country $H$. This pattern is based on zero difference between the technological levels of the regions, because otherwise at least one intra-national trade operation could occur.

In trade pattern 2 , regions $R_{1}$ to $R_{m}$ are arranged hierarchically in terms of technological level, and a region's demand for new intermediates is satisfied entirely by the neighboring region with higher-ranked technology. This implies a substantial regional technological inequality.

Trade pattern 2 is reduced to trade pattern 1 if $m$ trade layers are reduced to just one, and all regions branch into it. All possible realistic trade patterns can be regarded as mixtures of the two extreme cases. For example, the intermediate cases can occur if regions are located at different layers, and then clustered into groups in each layer. Trades occur between pairs of regions belonging to different groups and layers. If the number of regions is large, there can be many combinations. For example, in the case of China, 
the regions of Beijing, Shanghai, and Guangdong are three first-layer regions. Secondlayer regions trade with them, but the number of regions that do so varies, depending on geographical and others factors. Similarly, the number of regions that trade with each of the second-layer regions varies. Needless to say, a region can trade with many regions, further complicating the combinations. Therefore, a uniform presentation of network forms is impossible. To limit this to a specific case, we create a three-layer intra-national trade network, assuming each region trades only with two lower-level regions, as well as with one higher-level region. This yields the 14-region network illustrated in Figure 2.

\section{Figure 2. Intra-national trade network}

(A three-layer, and two-clustered region)

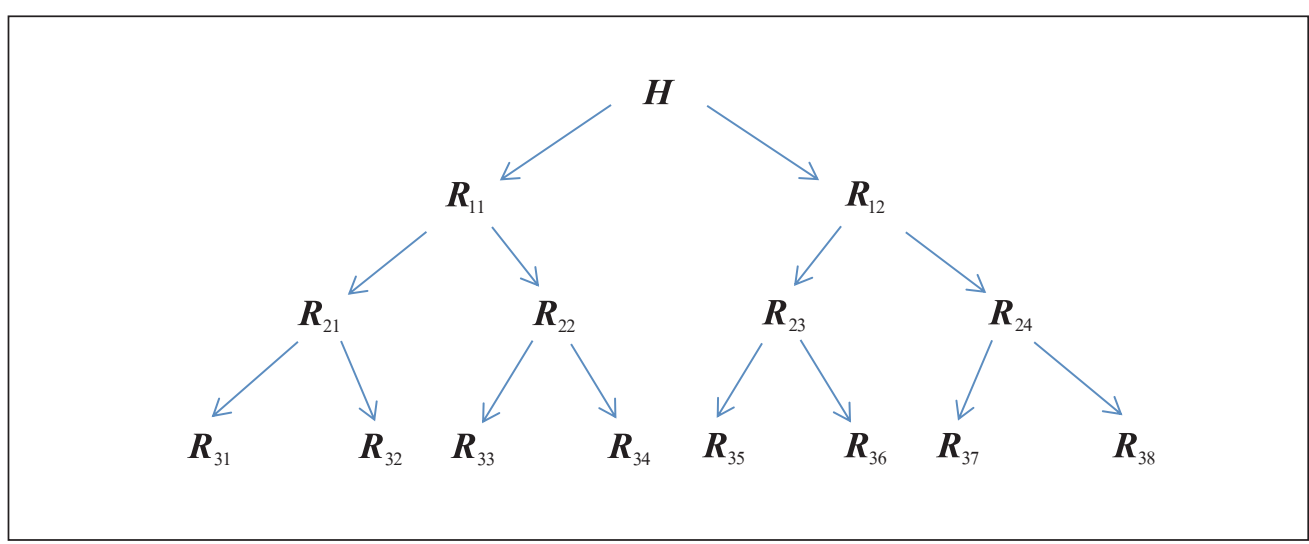

(Note) $H$ is the foreign country. The arrows reflect the export direction of new intermediates. Regions are denoted as $R_{m}$, where $l$ denotes the layer, and $m$ is the number of regions within the same layer. The technological levels are decreasing with the number of layers.

(Source) Author.

Within the trade network, if all pairs of trade partners have gone through their transitions and have arrived at their steady states, then the trade network is in its steady state. ${ }^{7}$ By definition, in the steady state, for each pair of trading partners, the importer of higher intermediates reaches the same growth rate as that of the exporter. In the steady

\footnotetext{
7 Although a formal approach to the steady state of the network with $m$ regions is difficult, its feasibility can be understood in an informal way. Its realization with trade pattern 1 is inductive. With trade pattern 2, we can infer that, to start with, $R_{1}$ gets to its steady state through trade with $H$, then $R_{2}$ gets to its steady state through trade with $R_{1}$, and so on, until, at last, $R_{m}$ gets to its steady state through trade with $R_{m-1}$. This procedure would take an exceedingly long time. The actual process could take place through simultaneous trades among regions, with the network steady state being achieved through mutual adjustments. This steady state exists logically, but mathematically is difficult to make tractable.
} 
state of the network, all regions will reach the same growth rate as that of the exporter with the highest technological level: the foreign country. Therefore, the key function of intra-national trade can be described as the operation of a spillover mechanism. The higher technologies spill over from the foreign country to the most advanced regions of the developing country through international trade. Then, intra-national trade drives these spillovers from the advanced regions to the less developed regions. In this way, intranational trade takes over from international trade in transferring innovations to locations where international linkages may be totally absent.

The spillover mechanism obviously works with trade pattern 1, and can also be demonstrated with trade pattern 2. In the steady state of the trade network, by Equation (16), $N_{1}^{*}=\frac{1}{T_{1} F_{1}}\left(G_{1} / G_{H}\right) N_{H}$. Because region 2 imports new intermediates from region 1 , this leads to $N_{2}^{*}=\frac{1}{T_{0}}\left(G_{2} / G_{1}\right) N_{1}^{*}=\frac{1}{T_{0} T_{1} F_{1}}\left(G_{2} / G_{H}\right) N_{H} \cdot 8$

By the same token, $N_{3}^{*}=\frac{1}{T_{0}}\left(G_{3} / G_{1}\right) N_{1}^{*}=\frac{1}{T_{0}^{2} T_{1} F_{1}}\left(G_{2} / G_{H}\right) N_{H}$, where $T_{0}$ appears twice.

Thus, in a more general pattern, for any region $i$ that engages in intra-national trade:

$$
N_{i}^{*}=\frac{1}{T_{0}^{g-1} T_{1} F_{1}}\left(G_{i} / G_{H}\right) N_{H}
$$

where $g$ is the number of layers of trade network region $i$.

Equation (22) describes the spillover effects received by the regions conducting intranational trade and, thus, can be called the intra-national spillover equation. At any layer $g$ of the trade network, the optimal number of varieties of intermediates will be altered by that of the highest layer. Even though, in the beginning, less developed regions have low growth rates, Equation (22) results in $\dot{N}_{i}^{*} / N_{i}^{*}=\dot{N}_{H} / N_{H}$, or the highest growth rate from the foreign country $H$ being transmitted to all levels of the trade network.

\footnotetext{
${ }^{8}$ Here, because $F_{0}$, the parameter scaling the assimilation cost, is minimized endogenously by regions by importing from advanced regions with lower technological distances, it is now assumed to be identical across regions and is normalized to 1 . In addition, $T_{i 1}$ is simplified to $T_{1}$. In other words, the international trade cost is assumed to be equal across regions, and is regarded as being constrained and coordinated by the central government.
} 


\section{F. Effect of internal trade costs}

The adjustments in trade costs, via the equations of motion shown in Equation (13.1) and Equation (14.1), produce a comparative dynamic effect. In the intra-national spillover Equation (22), trade costs are manifested in an inter-connected, or network, form. Within the intra-national trade network, the steady-state number of varieties of intermediates of each region is affected by its own trade cost, and by overall trade impediments in the form of the product of the trade costs of all higher-level regions in the network. In other words, the economic performance of each region is altered by direct and indirect internal trade costs within the network.

This network form of internal trade costs gives rise to an important implication: the reduction of internal trade costs exerts a stronger effect on regional economic performances than that of an equivalent lifting of border barriers. Equation (22) reveals that in the network of intra-national trade, internal trade costs exert a multiplied hindering effect on the performance of the regions at the lower layers of the network, which is higher than that of external trade costs. If the number of internal trade layers is $g$, the elasticity of the steady-state number of intermediates induced by the reduction of internal trade costs is $g-1$ times higher than that of the external trade costs. This makes intuitive sense: if the social planner imposes a change in trade costs at the national level, owing to trade interconnections, particularly for trade interdependence of technological goods, the policy effect will be amplified. The higher the technological inequality among the regions, and the larger the number of the trade layers, the stronger the effect of internal trade costs will be relative to the external trade costs through the intra-national spillover effects. This effect is especially strong for the least developed regions, because they are situated at the lowest layers of the trade network and, thus, bear a higher multiplier of internal costs.

This theoretical inference of a stronger effect of internal trade costs over external trade costs seems to be supported from the recent empirical work of Tombe and Zhu (2015). The authors estimated that in China between 2000 and 2005, internal trade costs fell, on average, by $10 \sim 15 \%$, while international costs fell by almost $10 \%$ in nonagriculture and nearly $25 \%$ in agriculture. Internal trade cost reductions account for onefifth of China's aggregate growth in real Gross Domestic Product (GDP) per worker. However, international trade liberalization accounts for only $7 \%$ of the growth. Their study measured the effects based on all trading products. If only technological inputs were considered, this difference should be larger still. 


\section{Empirical Support}

\section{A. Why China is an appealing case?}

In light of the previous analysis, we propose three theoretical hypotheses on intranational trade in developing countries, which are subject to empirical verification: 1) the intra-national trade ratio of a region is inversely proportional to its technological level; 2) the intra-national trade share of a country increases with the country's regional technological inequality; and 3) with intra-national trade, the high growth rate benefiting the advanced regions (country) spills over into the less developed regions.

In what follows, we use data on China to investigate whether these hypotheses are supported.

China has experienced long-lasting productivity growth (Zhu 2012). One factor that explains both China's development dynamism and its difficulties is the increasing regional disparity within the country (Kanbur and Zhang 2005, Fleisher, Li, and Zhao 2010). China is a large country, with 31 provinces and four municipalities directly under the jurisdiction of the central government. Conventionally, these provinces are classified into three large regions: the coastal region (10 provinces), central region (nine provinces), and western region (12 provinces). Tibet is excluded from this study owing to missing data. In 2007 , the regional population shares are $36.6 \%, 35.6 \%$, and $27.8 \%$, respectively, with GDP shares of $55.3 \%, 27.4 \%$, and $17.3 \%$, respectively.

The coastal region is the most developed, and is the main exporting region, followed by the central region and the western region, which is the least developed. Although the central government retains political control over the regions, the provinces are becoming economic and political agents, with their own economic and social agendas and distinct political and cultural identities (Hendrischke and Feng 1999).

Given the difficulties of gathering published data on intra-national trade by sector and by province, one possibility of dealing with intra-national trade empirically is to use provincial input-output tables. Regional input-output tables have long been employed as tools to analyze regional trade and development (for an introductory presentation, see Hoover and Giarratani 1999, chapter 11). China has published 2002 and 2007 provincial input-output tables. ${ }^{9}$ Those from 2007 are usable here because they show "inflows"

\footnotetext{
${ }^{9}$ The more recent 2010 provincial input-output tables are just extended tables, or an extension of those of 2007, with the main prices and consumption coefficients derived from the latter.
} 
(international imports plus inter-provincial imports) and "outflows" (international exports plus inter-provincial exports) by province and by sector. Together with the data on 2007 international trade by sector and by province, taken from the provinces' 2008 statistical yearbooks, we can use "inflows" to determine the inter- and intra-national import variables. The 2002 provincial input-output tables are not usable, because they provide only a "net flow," without distinguishing between "inflows" and "outflows."

As a function of this data availability, we investigate, in the next sections, two empirical situations related to the theoretical propositions.

First, in a developing country, the advanced regions are the main international importers of technological inputs, and the intra-national import ratios of these inputs are much higher in the less developed regions than they are in advanced regions. This is implied directly by proposition one. It is also implied indirectly by proposition two, because the latter is coupled with the share of the less developed regions being much more dependent on intra-national trade.

Second, owing to the connections between inter- and intra-national trades, the high growth rate benefiting the advanced regions (country) spills over into the less developed regions.

\section{B. Intra-national trade at the regional and national levels}

In this section, we introduce five tables derived from the 2007 provincial input-output tables, and describe the state of intra-national trade in China. Table 1 shows that China's intra-national trade was more important in terms of volume than was its foreign trade. Intra-national equipment imports accounted for about $60 \%$ of total imports. This ratio was even higher for manufactured goods and overall imports, with around two-thirds and three-fourths of the total, respectively. As a developing country with high regional inequality, Chinese intra-national trade is essentially based on comparative advantages, and plays a more important role than international trade does. At the same time, as a newly industrializing country, there is a growing share of intra-national trade, driven by increasing returns and agglomeration. 
Table 1. Indicators for China's intra-national trade

(in $2007, \%$ )

\begin{tabular}{|l|l|}
\hline Intra-national trade/GDP & 72.69 \\
\hline Intra-national trade/(Intra- + international trade) & 68.89 \\
\hline Intra-national imports/(Intra- + international imports) & 74.08 \\
\hline Intra-national manufacturing imports/(Intra- + international manufacturing imports) & 65.64 \\
\hline Intra-national equipment imports/(Intra- + international equipment imports) & 58.67 \\
\hline
\end{tabular}

(Note) (i) International equipment imports, manufacturing imports, and imports are calculated from 2008 statistical yearbooks of the provinces.

(ii) Intra-national equipment imports, manufacturing imports, and imports are computed based on the "inflows" by province and by sector in China's 2007 provincial input-output tables and using international trade data in the 2008 statistical yearbooks of the provinces.

(iii) Intra-national imports are specified as inter-provincial imports, and exclude intra-provincial imports.

Table 2 provides information on the trade structure of the three regions, showing that with regional disparity, the trade structures vary among the regions. The less developed western region had a higher share of imported manufactured and equipment goods than it did of exported goods, but a higher share of other goods (agricultural and raw material) in exports than it did in imports. This is a typical trade pattern in less developed countries (regions). The most developed coastal region had an opposite pattern. The middle-level central region had a mixture of the two. These differences in trade patterns are verified by the overall inflows and outflows, as well as by intra-national imports and exports. Exceptions exist in the international imports and exports, in which all three regions had a higher share of other goods in imports than they did in exports, and a higher share of manufactured goods in exports than they did in imports. This implies that all regions demand raw materials. 
Table 2. Shares of manufactured goods and equipment

(for the two types of trade by region, \%)

\begin{tabular}{|c|c|c|c|c|c|c|}
\hline & \multicolumn{3}{|c|}{ Inflow } & \multicolumn{3}{|c|}{ Outflow } \\
\hline & $\begin{array}{c}\text { Manufactured } \\
\text { goods }\end{array}$ & $\begin{array}{l}\text { Equipment } \\
\text { goods }\end{array}$ & $\begin{array}{l}\text { Other } \\
\text { goods }\end{array}$ & $\begin{array}{c}\text { Manufactured } \\
\text { goods }\end{array}$ & $\begin{array}{c}\text { Equipment } \\
\text { goods }\end{array}$ & $\begin{array}{l}\text { Other } \\
\text { goods }\end{array}$ \\
\hline Coastal region & 71.01 & 34.69 & 28.99 & 82.20 & 41.25 & 17.80 \\
\hline Central region & 63.56 & 31.17 & 36.44 & 68.61 & 19.85 & 31.39 \\
\hline Western region & 61.19 & 29.78 & 38.81 & 57.66 & 12.52 & 42.34 \\
\hline \multirow[t]{3}{*}{ Total } & 68.04 & 33.25 & 31.96 & 76.61 & 33.67 & 23.39 \\
\hline & \multicolumn{3}{|c|}{ International import } & \multicolumn{3}{|c|}{ International export } \\
\hline & $\begin{array}{c}\text { Manufactured } \\
\text { goods }\end{array}$ & $\begin{array}{l}\text { Equipment } \\
\text { goods }\end{array}$ & $\begin{array}{l}\text { Other } \\
\text { goods }\end{array}$ & $\begin{array}{c}\text { Manufactured } \\
\text { goods }\end{array}$ & $\begin{array}{l}\text { Equipment } \\
\text { goods }\end{array}$ & $\begin{array}{l}\text { Other } \\
\text { goods }\end{array}$ \\
\hline Coastal region & 79.51 & 47.94 & 20.49 & 95.52 & 55.20 & 4.48 \\
\hline Central region & 69.59 & 29.17 & 30.41 & 86.19 & 27.86 & 13.81 \\
\hline Western region & 65.40 & 30.69 & 34.60 & 93.50 & 24.11 & 6.50 \\
\hline \multirow[t]{3}{*}{ Total } & 78.35 & 46.06 & 21.65 & 94.71 & 51.83 & 5.29 \\
\hline & \multicolumn{3}{|c|}{ Intra-national import } & \multicolumn{3}{|c|}{ Intra-national export } \\
\hline & $\begin{array}{c}\text { Manufactured } \\
\text { goods }\end{array}$ & $\begin{array}{l}\text { Equipment } \\
\text { goods }\end{array}$ & $\begin{array}{l}\text { Other } \\
\text { goods }\end{array}$ & $\begin{array}{c}\text { Manufactured } \\
\text { goods }\end{array}$ & $\begin{array}{c}\text { Equipment } \\
\text { goods }\end{array}$ & $\begin{array}{l}\text { Other } \\
\text { goods }\end{array}$ \\
\hline Coastal region & 65.02 & 25.35 & 34.98 & 70.74 & 29.24 & 29.26 \\
\hline Central region & 62.89 & 31.39 & 37.11 & 65.47 & 18.41 & 34.53 \\
\hline Western region & 60.87 & 29.72 & 39.13 & 53.11 & 11.05 & 46.89 \\
\hline Total & 63.66 & 27.80 & 36.34 & 66.39 & 23.41 & 33.61 \\
\hline
\end{tabular}

(Note) (i) "Inflow" is equal to international imports plus inter-provincial imports, and "outflow" is equal to international exports plus inter-provincial exports.

(ii) International imports and exports of manufactured goods, equipment goods, and other goods are calculated from the 2008 statistical yearbooks of the provinces.

(iii) Intra-national imports and exports of manufactured goods, equipment goods, and other goods are computed from the "inflows" and "outflows" by province and by sector from China's 2007 provincial input-output tables and from the international trade data in the 2008 statistical yearbooks of the provinces.

(iv) Intra-national imports and exports are specified as inter-provincial imports and exports, while intraprovincial imports and exports are not included.

(v) The three regions are classified according to the conventional method, with 10 provinces in the coastal region, nine provinces in the central region, and 12 provinces in the western region. Tibet is excluded owing to a lack of data. 
Table 3 calculates the shares of the three regions in terms of national inter- and intranational imports. The table reveals that even if the coastal region had a higher share in both inter- and intra-national imports, its level of international imports is far more important. In contrast, in the central and (particularly) the western regions, the shares of intra-national imports (particularly in equipment) were higher than those of international imports. Because the intra-national imports (as shown in Table 2) are much higher than international imports, these high relative shares imply that less developed regions rely on intra-national rather than on international imports.

\section{Table 3. Shares of inter- and intra-national imports}

\begin{tabular}{|c|c|c|c|c|c|c|}
\hline & $\begin{array}{c}\text { Intra-national } \\
\text { imports }\end{array}$ & $\begin{array}{c}\text { International } \\
\text { imports }\end{array}$ & $\begin{array}{c}\text { Intra-national } \\
\text { manufactured } \\
\text { imports }\end{array}$ & $\begin{array}{c}\text { International } \\
\text { manufactured } \\
\text { imports }\end{array}$ & $\begin{array}{c}\text { Intra-national } \\
\text { equipment } \\
\text { imports }\end{array}$ & $\begin{array}{c}\text { International } \\
\text { equipment } \\
\text { imports }\end{array}$ \\
\hline $\begin{array}{c}\text { Coastal } \\
\text { region }\end{array}$ & 54.19 & 89.76 & 55.34 & 91.09 & 49.41 & 93.41 \\
\hline $\begin{array}{c}\text { Central } \\
\text { region }\end{array}$ & 26.70 & 6.91 & 26.38 & 6.13 & 30.16 & 4.37 \\
\hline $\begin{array}{c}\text { Western } \\
\text { region }\end{array}$ & 19.11 & 3.33 & 18.28 & 2.78 & 20.43 & 2.22 \\
\hline Total & $\mathbf{1 0 0}$ & $\mathbf{1 0 0}$ & $\mathbf{1 0 0}$ & $\mathbf{1 0 0}$ & $\mathbf{1 0 0}$ & $\mathbf{1 0 0}$ \\
\hline
\end{tabular}

(Note) (i) International imports and exports of manufactured goods, equipment goods, and other goods are calculated from the 2008 statistical yearbooks of the provinces.

(ii) Intra-national imports and exports of manufactured goods, equipment goods, and other goods are computed from the "inflows" and "outflows" by province and by sector from China's 2007 provincial input-output tables and from international trade data in the provinces' 2008 statistical yearbooks.

(iii) Intra-national imports and exports are specified as inter-provincial imports and exports, and intraprovincial imports and exports are not included.

(iv) Three regions are identified using conventional method, with 10 provinces in the coastal region, nine provinces in the central region, and 12 provinces in the eastern region. Tibet is excluded.

Table 4 illustrates that between inter- and intra-national imports, the coastal region had a higher share of international imports, and that this share was even higher $(57 \%)$ for equipment imports. It also had a high share of intra-national imports owing to withinregion disparity in the coastal region. Those provinces in the coastal region with lower technological levels also had a strong demand for goods from the other, more advanced provinces. The most striking finding is that in the western region, and even in the central 
region, the demand for international imports was very weak (lower than $10 \%$ ), while intra-national imports remained dominant.

\section{Table 4. Shares of inter-and intra-national imports}

(by region, \%)

\begin{tabular}{|c|c|c|c|c|c|c|c|c|c|}
\hline & $\begin{array}{c}\text { Intra- } \\
\text { national } \\
\text { imports }\end{array}$ & $\begin{array}{c}\text { International } \\
\text { imports }\end{array}$ & Total & $\begin{array}{c}\text { Intra- } \\
\text { national } \\
\text { manufactured } \\
\text { imports }\end{array}$ & $\begin{array}{c}\text { International } \\
\text { manufactured } \\
\text { imports }\end{array}$ & Total & $\begin{array}{c}\text { Intra- } \\
\text { national } \\
\text { equipment } \\
\text { imports }\end{array}$ & $\begin{array}{c}\text { International } \\
\text { equipment } \\
\text { imports }\end{array}$ & Total \\
\hline $\begin{array}{c}\text { Coastal } \\
\text { region }\end{array}$ & 58.66 & 41.34 & $\mathbf{1 0 0}$ & 53.72 & 46.28 & $\mathbf{1 0 0}$ & 42.87 & 57.13 & $\mathbf{1 0 0}$ \\
\hline $\begin{array}{c}\text { Central } \\
\text { region }\end{array}$ & 90.09 & 9.91 & $\mathbf{1 0 0}$ & 89.15 & 10.85 & $\mathbf{1 0 0}$ & 90.72 & 9.28 & $\mathbf{1 0 0}$ \\
\hline $\begin{array}{c}\text { Western } \\
\text { region }\end{array}$ & 93.09 & 6.91 & $\mathbf{1 0 0}$ & 92.61 & 7.39 & $\mathbf{1 0 0}$ & 92.88 & 7.12 & $\mathbf{1 0 0}$ \\
\hline
\end{tabular}

(Note) (i) International imports and exports of manufactured goods, equipment goods, and other goods are calculated from the 2008 statistical yearbooks of the provinces.

(ii) Intra-national imports and exports of manufactured goods, equipment goods, and other goods are computed from the "inflows" and "outflows" by province and by sector from China's 2007 provincial input-output tables and from international trade data in the provinces' 2008 statistical yearbooks.

(iii) Intra-national imports and exports are specified as inter-provincial imports and exports, and intraprovincial imports and exports are not included.

(iv) Three regions are identified using to the conventional method, with 10 provinces in the coastal region, nine provinces in the central region, and 12 provinces in the western region. Tibet is excluded.

Another way of comparing the types of trade is to check the net imports (imports less exports). Table 5 shows that the coastal region was a net intra-national exporter. In contrast, the central and, particularly, the western region is a net intra-national importer of manufactured and equipment goods.

\footnotetext{
${ }^{10}$ Note that the sum of the three regions' interprovincial net exports is not zero because these transactions include intraregional trade.
} 
Table 5. Net imports

(by regions, in billions US dollars)

\begin{tabular}{|c|c|c|c|c|}
\hline & $\begin{array}{c}\text { International } \\
\text { (manufactured) }\end{array}$ & $\begin{array}{c}\text { Intra-national } \\
\text { (manufactured) }\end{array}$ & $\begin{array}{c}\text { International } \\
\text { (equipment) }\end{array}$ & $\begin{array}{c}\text { Intra-national } \\
\text { (equipment) }\end{array}$ \\
\hline Coastal region & -332.1 & -79.8 & -174.7 & -51.7 \\
\hline Central region & -36 & 30.9 & -7.2 & 91.4 \\
\hline Western region & -22.8 & 67.2 & -1.4 & 87.6 \\
\hline
\end{tabular}

(Note) (i) International imports and exports of manufactured goods, equipment goods, and other goods are calculated from the 2008 statistical yearbooks of the provinces.

(ii) Intra-national imports and exports of manufactured goods, equipment goods, and other goods are computed from the "inflows" and "outflows" by province and by sector from China's 2007 provincial input-output tables and from international trade data in the provinces' 2008 statistical yearbooks.

(iii) Intra-national imports and exports are specified as inter-provincial imports and exports, and intraprovincial imports and exports are not included.

(iv) Three regions are identified using the conventional method, with 10 provinces in the coastal region, nine provinces in the central region, and 12 provinces in the western region. Tibet is excluded.

These descriptive statistics illustrate that China's less developed provinces relied mainly on domestic trade to satisfy their needs, and especially for filling their technological gap in that period. The advanced provinces were at once intra-nationally net exporters and internationally net importers, especially in equipment inputs.

\section{Intra-national spillovers}

With the one-period data, tests on intra-national spillover effects, in a strict sense, are not possible. Panel data with multiple periods and various trade levels are required. In seeking to verify the intra-national spillover effects from the standpoint of the convergence of the growth rates among regions, it is observed that the average 2007 nominal GDP growth rates of the coastal, central, and western regions were $14.7 \%$, $14.4 \%$, and $13.7 \%$ respectively, without significant divergence.

The existence of spillover effects in China is supported by extensive studies on the impact of Foreign Direct Investment (FDI) (Cheung and Lin 2004, Liu 2007, Lin, Liu, and Zhang 2009). Another line of thought, namely spillover effects via human capital in China, also provide interesting results (Kuo and Yang 2008, Fleisher, Li, 
and Zhao 2010). A handful of studies have explored the topic of Chinese interregional spillovers from different angles. Ying (2000) used a spatial data analysis to show growth correlations between Guangdong and four of the five contiguous provinces. Zhang and Felmingham (2002) addressed the issue of relationship between exports, FDI, and growth. Brun, Combes, and Renard (2002) examined growth convergence. The studies all found evidence of spillovers from the coastal to the central region. Groenewold, Lee, and Chen (2008) employed a Vector Autoregressive (VAR) model with six regions as a framework for a dynamic simulation of the effects of a shock in one region on other regions. The National Information Center (2005) built an input-output table for 1997 for eight regions, and calculated the interregional industrial multipliers, incorporating backward and forward linkages. Ouyang and $\mathrm{Fu}$ (2012) found that inter-regional spillovers from FDI concentrated in China's coastal cities had a positive and significant effect on the growth of inland cities.

\section{Policy Implications}

This study suggests that in developing countries with a large number of less developed regions, the prevalence for intra-national trade is their rational choice. Intra-national trade is a feasible way to improve their technologies. Otherwise, given their limited capabilities in assimilation, they would be excluded from international technological spillovers. Therefore, intra-national trade is caused by a comparative advantage, and is shaped by regional differences in technological levels.

The effect of intra-national trade is also different in developing countries compared with that in developed countries. In developing countries, intra-national trade prolongs international spillovers. This transmission process of an intra-national trade network is shown to be a powerful pro-development mechanism. Intra-national trade spillovers could be weak in developed countries owing to their narrow regional disparity.

The policy implications of this study can be assessed based on the central importance of intra-national trade in the developing world. In development economics, much of the work so far has focused on international trade and openness. This study offers an alternative view that intra-national trade, especially in its connection with international trade, provides a key development mechanism. 
With the differences in causes and effects of intra-national trade, border effects, for instance, could be different between developed and developing countries. In a developed country, with modest regional disparity, the differences in assimilation costs between regions are no longer a factor in determining intra-national trade. Furthermore, owing to their modern institutional structure, internal trade barriers are no longer a serious concern. Therefore, border barriers are the key determinant for the choice between the two types of trade. In a developing economy, the fall of international barriers could increase demand for international imports, to some extent, in the most advanced regions, but has minor impact on the demand in less developed regions. This is because this demand is basically internal-oriented and is determined by the difference in the assimilation costs between the two types of trade. The larger the number of less developed regions, the weaker the border effect will be.

Another far-reaching policy implication stemming from the multiplied effect of internal trade costs is that without a well-performing intra-national trade network, openness brings international technological spillovers into a small number of advanced regions only. Thus, it not only exerts a limited effect at the country level, but also exacerbates regional disparity. A reduction in border barriers could mostly affect the demand of some advanced regions for international imports. The fall of internal trade barriers will affect intra-national imports by increasing the demand for technological innovation in less developed regions. This effect could be more important if the developing country's regional disparity is wider. Given that an intrinsic feature of the developing world is its underdeveloped institutional infrastructure, efforts to improve internal market integration by reducing internal trade costs take on a major importance.

The policy implications derived from the model seem to agree with the findings of a number of empirical works. On the central importance of intra-national trade in the developing world, $\mathrm{Fu}, \mathrm{Fu}$, and $\mathrm{Li}$ (2008) found intra-national technology transfer is more important than that taking place through FDI in backward regions. On the need to reduce internal trade costs, Tombe and Zhu (2015) estimated that a reduction in internal costs contributed much more to GDP growth than did a reduction in international trade costs. Empirical studies on intra-national spillovers have until now focused on China. Extensions to other developing countries will be valuable to enriching our understanding on this issue. 


\section{Conclusions}

This study built a comparative advantage-based trade framework and showed that, first, in a typical developing country, the choices between inter- and intra-national trades by regions are determined endogenously as a function of the regions' technological capabilities, and that the country's intra-national trade share is shaped by regional disparity. Second, there exists a mechanism of intra-national spillovers. With an intra-national trade network, high growth achieved by the advanced regions through international imports of new intermediates is transmitted to the less developed regions, even though the latter has no international contact. Third, internal trade costs exert a multiplied hindering effect, which is stronger than that of border barriers, on national growth. We found empirical support for these propositions based on 2007 Chinese provincial input-output tables, and on a number of empirical studies.

Whereas the study model investigated a major aspect of comparative-advantage based intra-national trade in the developing world, it suffers a limitation of ruling out increasing returns and agglomeration that play an, albeit weaker, increasing role in determining intra-national trade in developing countries. With the reduction of regional technological disparity, interregional trade could be driven by specialization and intraindustrial exchange. New economic geography provides tools for analyzing the dynamic perspective of regional trade in newly industrialized countries. In such countries, following Venables (2005), spatial inequality is not only due to natural advantages, but also to the presence of agglomeration forces, leading to a clustering of activities. In these economies, external trade could also give rise to internal industrial clustering (Krugman and Hanson 1993). Krugman (2015) further examined a collection of locations in China's export industries, with each town dominating world production of one type of product. A meaningful extension of this study would be to explore the evolution of intranational trade with the interplay between comparative advantage and agglomeration as driving forces. This will require a more sophisticated construction, and is beyond the scope of this study.

Received 7 March 2017, Revised 30 March 2017, Accepted 25 April 2017 


\section{References}

Amiti, Mary, and Jozef G. Konings. "Trade Liberalization, Intermediate Inputs, and Productivity: Evidence from Indonesia.” The American Economic Review 97 (2007): 1611-38.

Anderson, James E., and Eric van Wincoop. "Gravity with Gravitas: A Solution to the Border Puzzle." The American Economic Review 93 (2003): 170-92.

Barro, Robert J., and Xavier Sala-i-Martin. Economic Growth. Cambridge MA: MIT Press, 2004.

Betts, Caroline, and Michael B., Devereux. "The Exchange Rate in a Model of Pricing-toMarket." European Economic Review 40 (1996): 1007-22.

Blalock, Garrick, and Francisco Veloso. "Imports, Productivity Growth, and Supply Chain Learning." World Development 35 (2007): 1134-51.

Brun Jean-Francois, Jean-Louis Combes, and Mary-Françoise Renard. "Are There Spillover Effects between Coastal and Noncoastal Regions in China?" China Economic Review 13 (2002): 161-69.

Cheung, Kui Y., and Ping Lin. "Spillover Effects of FDI on Innovation in China: Evidence from the Provincial Data." China Economic Review 15 (2004): 25-44.

Combes, Pierre-Philippe, Thierry Mayer, and Jacques-François Thisse. Economic Geography, the Integration of Regions and Nations. Princeton and Oxford: Princeton University Press, 2008.

Costinot, Arnaud "An Elementary Theory of Comparative Advantage." Econometrica 77 (2009): 1165-92.

Cronon, William. Nature's Metropolis, Chicago and the Great West. London: W. W. Norton, 1991.

Devereux, Michael B. "Real Exchange Rates and Macroeconomics: Evidence and Theory." Canadian Journal of Economics 30 (1997): 773-808.

Dollar, David. "Technological Innovation, Capital Mobility, and the Product Cycle in North-South Trade." The American Economic Review 76 (1986): 177-90.

Ethier, Wilfred J. "National and International Returns to Scale in the Modern Theory of 
International Trade." American Economic Review 72 (1982): 389-405.

Feenstra, Robert C., James R. Markusen, and William Zeile. "Accounting for Growth with New Inputs: Theory and Evidence.” The American Economic Review 82 (1992): 415-21.

Felbermayr, Gabriel J., and Toubal Farid. "Cultural Proximity and Trade." European Economic Review 54 (2010): 279-93.

Fernandes, Ana M. "Trade Policy, Trade Volumes, and Plant-level Productivity in Colombian Manufacturing Industries." Journal of International Economics 71 (2007): $52-71$.

Findlay, Ronald. "Relative Less Developedness, Direct Foreign Investment, and the Transfer of Technology: A Simple Dynamic Model.” The Quarterly Journal of Economics 92 (1978): 1-16.

Fleisher, Belton, Haizheng Li, and Minqiang Zhao. "Human Capital, Economic Growth, and Regional Inequality in China." Journal of Development Economics 92 (2010): 215-31.

Fu, Miao, Xiaolan Fu, and Tieli Li. "International and Intra-national Technology Spillovers and Technology Development Paths in Developing Countries: the Case of China.” WIDER Working Paper, no. 096, World Institute for Development Economic Research (UNU-WIDER), 2008.

Fujita, Masahisa, Paul R. Krugman, and Antony J. Venables. The Spatial Economy: Cities, Regions, and International Trade. Cambridge MA: MIT Press, 1999.

Groenewold, Nicolaas, Guoping Lee, and Anping Chen. "Inter-regional Spillovers in China: the Importance of Common Shocks and the Definition of the Regions." China Economic Review 19(2008): 32-52.

Grossman, Gene M. "Trade, Knowledge Spillovers and Growth.” European Economic Review Papers and Proceedings 35 (1991): 517-26.

Hendrischke, Hans J., and Chongyi Feng, eds. The Political Economy of China's Provinces: Comparative and Competitive Advantage. New York: Routledge, 1999.

Hoover, Edgar M., and Frank Giarratani. An Introduction to Regional Economics. The Web book of Regional Science, Regional Research Institute, West Virginia University, 1999. Accessed April 10, 2017. http://www.rri.wvu.edu/WebBook/Giarratani/ preface.htm. 
Isard, Walter . Location and Space-economy. Cambridge MA: MIT Press, 1956.

Isard, Walter, and Peck J. Merton. "Location Theory and International and Interregional Trade Theory." The Quarterly Journal of Economics 68 (1954): 97-114.

Kanbur, Ravi, and Xiaobo Zhang. "Fifty Years of Regional Inequality in China: a Journey Through Central Planning, Reform, and Openness." Review of Development Economics 9 (2005): 87-106.

Kasahara, Hiroyuki, and Joel Rodrigue. "Does the Use of Imported Intermediates Increase Productivity? Plant-level Evidence." Journal of Development Economics 87 (2008): 10618.

Keller, Wolfgang. "The Geography and Channels of Diffusion at the World's Technology Frontier.” NBER Working Paper, no. W8150, 2001.

Krugman, Paul R. "A Model of Innovation, Technology Transfer, and the World Distribution of Income.” Journal of Political Economy 87 (1979): 253-65.

Krugman, Paul R. Geography and Trade. Cambridge MA: MIT Press, 1991a.

Krugman, Paul R. "Increasing Returns and Economic Geography." Journal of Political Economy 99 (1991b): 483-99.

Krugman, Paul R. "Interregional and International Trade: Different Causes, Different Trends?" in Regional Science Matters, edited by Nijkamp, Peter, Rose Adam, and Kourtit Karima, 27-34. Switzerland: Springer International Publishing, 2015.

Krugman, Paul R., and Gordon Hanson. "Mexico-U.S. Free Trade and the Location of Production." in The Mexico-U.S. Free Trade Agreement, edited by Garber, Peter M. Cambridge MA: MIT Press, 1993.

Kuo, Chun-Chien, and Chih-Hai Yang. "Knowledge Capital and Spillover on Regional Economic Growth: Evidence from China." China Economic Review 19 (2008): 594-604.

Lessmann, Christian. "Spatial Inequality and Development - Is There an Inverted-U Relationship?” Journal of Development Economics 106 (2014): 35-51.

Lin, Ping, Zhuomin Liu, and Yifan Zhang. "Do Chinese Domestic Firms Benefit from FDI Inflow? Evidence of Horizontal and Vertical Spillovers." China Economic Review 20 (2009): 677-91. 
Liu, Zhiqiang. "Foreign Direct Investment and Technology Spillovers: Theory and Evidence.” Journal of Development Economics 85 (2007): 176-93.

National Information Center. Multi-regional Input-output Model for China (zhongguo quyujian touruchanchubiao). Beijing: Social Sciences Academic Press, 2005.

McCallum, John. "National Borders Matter: Canada-U.S. Regional Trade Patterns." The American Economic Review 85 (1995): 615-23.

Melitz, Jacques. "Language and Foreign Trade.” European Economic Review 52 (2008): 667-99.

Ohlin, Bertil. Interregional and International Trade. revised edition (1966). Cambridge MA: Harvard University Press, 1933.

Ouyang, Puman, and Shihe Fu. "Economic Growth, Local Industrial Development and Inter-regional Spillovers from Foreign Direct Investment: Evidence from China." China Economic Review 23 (2012): 445-60.

Poncet, Sandra. "A Fragmented China: Measure and Determinants of Chinese Domestic Market Disintegration." Review of International Economics 13 (2005): 409-30.

Romer, Paul M. "Endogenous Technological Change.” Journal of Political Economy 98 (1990): 71-102.

Schmidt, Wallace V., Roger N. Conaway, Susan S. Easton, and William J. Wardrope. Communicating Globally: Intercultural Communication and International Business. Thousand Oaks, CA: Sage Publications, 2007.

Tombe, Trevor T., and Xiaodong Zhu. 2015. "Trade, Migration and Productivity: A Quantitative Analysis of China." Working Paper, no. 542, Department of Economics, University of Toronto. Accessed April 10, 2017. https://www.economics.utoronto.ca/ public/workingPapers/tecipa-542.pdf.

Venables, Anthony J. "Spatial Disparities in Developing Countries: Cities, Regions and International Trade." in Ravi. Kanbur and Anthony J Venables, eds. Journal of Economic Geography, Special Issue Spatial Inequality and Development 5 (2005).

Wei, ShangJin. "Intra-national Versus International Trade: How Stubborn Are Nations in Global Integration?” NBER Working Papers, no. 5531, 1996.

Williamson, Jeffrey G. "Regional Inequality and the Process of National Development: 
A Description of the Patterns." Economic Development and Cultural Change 13 (1965): $1-84$.

World Bank. China Integration of National Product and Factor Markets Economic Benefits and Policy Recommendations. Document of the World Bank Report, no. 31973CHA. Washington DC: World Bank, 2005.

Ying, Long Gen "Measuring the Spillover Effects: Some Chinese Evidence.” Papers in Regional Science 79 (2000): 75-89.

Young, Alwyn. “The Razor's Edge: Distortions and Incremental Reform in the People's Republic of China." Quarterly Journal of Economics 115 (2000): 1091-135.

Zhang, Qing, and Bruce Felmingham. "The Role of FDI, Exports and Spillover Effects in the Regional Development of China." The Journal of Development Studies 38 (2002): 157-178.

Zhu, Xiaodong. "Understanding China's Growth: Past, Present, and Future.” Journal of Economic Perspectives 26 (2012): 103-24. 


\section{Appendix}

This appendix shows how Equation (16) is derived.

Using Equation (13.1), with region $i$ importing from the advanced region (or foreign country) $h$, and because $\dot{\hat{N}}_{i} / \widehat{N}_{i}=\dot{N}_{i} / N_{i}-\dot{N}_{h} / N_{h}$, we have:

$$
\frac{\dot{\hat{N}}_{i}}{\widehat{N}_{i}}=\frac{1}{T_{i} F_{i} \eta_{i} \widehat{N}_{i}}\left[\pi_{i} \frac{(1+\alpha)}{\alpha}-\chi_{i}\right]-\gamma_{h}
$$

where $\chi_{i}=C_{i} / N_{i}$ and $\gamma_{h}=\dot{N}_{h} / N_{h}$ is the growth rate of $N$ of region (foreign country) $h$. Substituting $\dot{\hat{N}}_{i} / \widehat{N}_{i}$ from Equation (A1) into Equation (14.1) produces:

$$
\frac{\dot{C}_{i}}{C_{i}}=\frac{1}{\theta}\left\{\frac{\pi_{i}}{T_{i} F_{i} \eta_{i} \widehat{N}_{i}}+\frac{1}{T_{i} F_{i} \eta_{i} \widehat{N}_{i}}\left[\pi_{i} \frac{(1+\alpha)}{\alpha}-\chi_{i}\right]-\gamma_{h}-\rho\right\}
$$

Since $\dot{\chi}_{i} / \chi_{i}=\dot{c}_{i} / c_{i}-\dot{N}_{i} / N_{i}$, substituting $\dot{c}_{i} / c_{i}$ from Equation (14.2) and $\dot{N}_{i} / N_{i}$ from Equation (13.1), yield:

$$
\frac{\dot{\chi}_{i}}{\chi_{i}}=\frac{1}{\theta}\left\{\frac{\pi_{i}}{T_{i} F_{i} \eta_{i} \widehat{N}_{i}}+\frac{1}{T_{i} F_{i} \eta_{i} \widehat{N}_{i}}\left[\pi_{i} \frac{(1+\alpha)}{\alpha}-\chi_{i}\right]-\gamma_{h}-\rho\right\}-\frac{1}{T_{i} F_{i} \eta_{i} \widehat{N}_{i}}\left[\pi_{i} \frac{(1+\alpha)}{\alpha}-\chi_{i}\right] .
$$

With $\dot{\hat{N}}_{i} / \widehat{N}_{i}=0$ in Equation (A1) and $\dot{\chi}_{i} / \chi_{i}=0$ in Equation (A2) in the steady state, solve for $\chi_{i}$ in both equations, and then, using $\pi_{i}$ in Equation (5.1), equate the two expressions for $\chi_{i}$, and rearrange. Then, we have:

$$
\widehat{N}_{i}^{*}=\frac{\pi_{i}}{\eta_{i} T_{i} F_{i}\left(\gamma_{h} \theta+\rho\right)}=\frac{L_{i} A_{i}^{1 /(1-\alpha)}(1-\alpha) \alpha^{(1+\alpha) /(1-\alpha)}}{\eta_{i} T_{i} F_{i}\left(\gamma_{h} \theta+\rho\right)}=\frac{L_{i}(1-\alpha) \alpha^{(1+\alpha) /(1-\alpha)}}{T_{i} F_{i}\left(\gamma_{h} \theta+\rho\right)} G_{i},
$$

where $\widehat{N}_{i}^{*}$ is the steady-state value of $\widehat{N}_{i}$, and $G_{i}=\frac{A_{i}^{1 /(1-\alpha)}}{\eta_{i}}$.

From Equation (14), and as it can be readily shown that the growth rates of production and consumption are the same in the steady state, we have

$$
\gamma_{h}=\frac{1}{\theta}\left(\frac{\pi_{h}}{\eta_{h}}-\rho\right)
$$


From Equation (5.1), the profit flow of region (foreign country) $h$ is:

$$
\pi_{h}=L_{h} A_{h}^{1 /(1-\alpha)}(1-\alpha) \alpha^{(1+\alpha) /(1-\alpha)}
$$

Then using $G_{h}=\frac{A_{h}^{1 /(1-\alpha)}}{\eta_{h}}$, we have

$$
\frac{\pi_{h}}{\eta_{h}}=L_{h}(1-\alpha) \alpha^{(1+\alpha) /(1-\alpha)} G_{h} .
$$

Using Equation (5.3) to substitute out for $\pi_{h} / \eta_{h}$ in Equation (A3.1), always holding $L_{h}=L_{i}=L$, yields:

$$
\widehat{N}_{i}^{*}=\frac{1}{T_{i} F_{i}} \frac{G_{i}}{G_{h}} .
$$

With $\dot{\hat{N}}_{i} / \widehat{N}_{i}=0$ in Equation (A1) and $\dot{\chi}_{i} / \chi_{i}=0$ in Equation (A2) in the steady state, solve for $\widehat{N}_{i}$ in both equations, and then using $\pi_{i}$ in Equation (5.1), equate the two expressions for $\widehat{N}_{i}$, and rearrange. This gives:

$$
\chi_{i}^{*}=\pi_{i}\left(\frac{1+\alpha}{\alpha}+\frac{\gamma_{h}}{\gamma_{h} \theta+\rho}\right) .
$$

